\title{
Challenges to creating primary care teams in a public sector health centre: a co-operative inquiry
}

\author{
Mash B, MBChB, MRCGP, DRCOG, DCH, PhD, \\ Associate Professor, Division of Family Medicine and Primary Care, Stellenbosch University \\ Mayers $\boldsymbol{P}$, MScMed (Psych), BA (Nursing), BCur, Senior Lecturer, Division of Nursing and Midwifery, University of Cape Town \\ Conradie $\boldsymbol{H}, \mathrm{MBChB}, \mathrm{DCH}, \mathrm{MPraxMed}$, Senior Family Physician, Eben Dönges Hospital, Worcester; \\ Senior Lecturer in Division of Family Medicine and Primary Care, Stellenbosch University \\ Orayn A, Diploma in Professional Nursing, Certificate in Primary Health Care, Diploma In Public Health Facility Manager, \\ Provincial Government of Western Cape, Worcester Community Health Centre \\ Kuiper M, MBChB, Principal Medical Officer, Worcester Community Health Centre \\ Marais J, Diploma in General Nursing, Diploma in Midwifery, Certificate in Primary Health Care \\ Chief Professional Nurse, Worcester Community Health Centre \\ Cornelissen B, Chief Administrator, Worcester Community Health Centre \\ Titus S, BCur. Certificate in Primary Health Care, Diploma in Nursing Administration \\ Facility Manager, Breede Valley Municipality, Worcester Community Health Centre \\ Correspondence to: Prof Bob Mash, E-mail: rm@sun.ac.za
}

\section{Abstract}

\section{Background}

Effective teamwork between doctors and clinical nurse practitioners (CNP) is essential to the provision of quality primary care in the South African context. The Worcester Community Health Centre $(\mathrm{CHC})$ is situated in a large town and offers primary care to the rural Breede Valley Sub-District of the Western Cape. The management of the $\mathrm{CHC}$ decided to create dedicated practice teams offering continuity of care, family-orientated care, and the integration of acute and chronic patients. The teams depended on effective collaboration between the doctors and the CNPs.

\section{Methods}

A co-operative inquiry group, consisting of two facility managers, an administrator, and medical and nursing staff, met over a period of nine months and completed three cycles of planning, action, observation and reflection. The inquiry focused on the question of how more effective teams of doctors and clinical nurse practitioners offering clinical care could be created within a typical $\mathrm{CHC}$.

\section{Results}

The $\mathrm{CHC}$ established three practice teams, but met with limited success in maintaining the teams over time. The group found that, in order for teams to work, the following are needed:

A clear and shared vision and mission amongst the staff. The vision was championed by one or two leaders rather than developed collaboratively by the staff. Continuity of care was supported by the patients and doctors, but the CNPs felt more ambivalent. Familyorientated care within practices met with limited success. Integration of care was hindered by physical infrastructure and the assumptions regarding the care of "chronics". Enhanced practitioner-patient relationships were reported by the two teams that had staff consistently available.

Significant changes in the behaviour and roles of staff. Some doctors perceived the nurse as an "assistant" who could be called on to run errands or perform tasks. Doctors perceived their own role as that of comprehensively managing patients in a consultation, while the CNPs still regarded themselves as nurses who should rotate to other duties and perform a variety of tasks, thus oscillating between the role of practitioner and nurse. The doctors felt responsible for seeing a certain number of patients in the time they were available, while the CNPs felt responsible for getting all the patients through the $\mathrm{CHC}$. The doctors did not create space for mentoring the CNPs, who were often seen as an intrusion and a threat to patient privacy and confidentiality when requesting a consultation. For the CNPs, however, the advantage of practice teams was considered to be greater accessibility to the doctor for joint consultation. The identification of doctors and CNPs with each other as part of a functioning team did not materialise.

Effective management of the change process implied the need to ensure sufficient staff were available to allow all teams to function equally throughout the day, to be cognisant of the limitations of the building design, to introduce budgeting that supported semi-autonomous practice teams and to ensure that the staff were provided with ongoing opportunities for dialogue and communication. The implications of change for the whole system should be considered, and not just that for the doctors and nurses.

\section{Conclusion}

Key lessons learnt included the need to engage with a transformational leadership style, to foster dialogical openness in the planning process and to address differences in understanding of roles and responsibilities between the doctors and the CNPs. The unreliable presence of doctors within the practice team, due to their hospital duties, was a critical factor in the breakdown of the teams. The $\mathrm{CHC}$ plans to further develop practice teams, to learn from the lessons so far and to continue with the co-operative inquiry.

SA Fam Pract 2007;49(1):17 


\section{Introduction}

The South African health system is characterised by a public sector that provides care to $80 \%$ of the population. ${ }^{1}$ The provision of primary health care is the cornerstone of health policy in South Africa and central to health service transformation. ${ }^{2}$ Primary care is conceived as being nurse-driven, with support from doctors, and therefore the clinical nurse practitioner (CNP) is central to the realisation of policy. In rural areas, this support may be located in the district hospital, while in urban areas it may be located within the community health centre $(\mathrm{CHC})$ alongside the CNP. The CNP is a registered nurse who has received post-registration training in diagnostics and in the treatment and referral of patients at primary level. Internationally, the fully trained family physician has been recognised as a key component of district health systems, one who provides quality care, supports rational decision making, communicates effectively and contributes towards district-level public health initiatives and management. ${ }^{3,4}$ The functioning of doctors and CNPs as effective teams within the district health system therefore is essential.

Although doctors and nurses often work alongside each other in the district health system, it cannot be assumed that they share the same values and perspectives as a basis for collaboration and teamwork. Indeed, the literature points to a host of factors that may predict important differences. These factors include the historical roots of the professions, gender differences, different socio-economic backgrounds, different professional socialisation, different educational models, ${ }^{4}$ and language. ${ }^{5} \mathrm{Al}$ though significant differences in values and perspectives are therefore likely, it also appears that doctors and nurses may collude in an interactional "game", with unwritten rules of hierarchy, which forbids open disagreement or dialogue. ${ }^{6}$ However, failure to interact effectively creates an unhealthy working environment and impacts negatively on patient care. $^{7}$ The widely promoted concept of interdisciplinary teamwork is often difficult to demonstrate in practice. ${ }^{8}$

In terms of their relative roles, Long et al. cite studies by Mundinger et al. and Kinnerlsey et al. that compared the effectiveness of nurse practitioners with general practitioners in a developed country setting, and concluded that CNPs appear to offer longer consultations with more investigations, more follow up, more information and more patient satisfaction. ${ }^{9}$ In essence, they found that CNPs are as safe as doctors for self-limiting illnesses, but are less productive and not necessarily cheaper. ${ }^{10}$ In the urban areas of South Africa, up to $57 \%$ of trained CNPs may not be functioning as practitioners due to a lack of motivation, a shortage of other categories of nursing staff, the lack of financial reward, a lack of confidence and fear of litigation. ${ }^{11}$ Kapp and Mash also highlighted a lack of teamwork, with doctors and CNPs working in isolation and seeing patients from the same pool, without any clearly defined relationship or differentiation of expertise. ${ }^{11}$ For nurses, trained for the most part in a task-orientated approach (an organisational practice in which nursing care is typically broken down into a series of tasks performed by different practitioners ${ }^{12}$ ), working in practice teams may be unfamiliar and threatening, as each CNP is then fully responsible for the comprehensive care of a patient. In addition, their different roles are more explicit when doctors and nurses work together in the same practice team.

This study was conducted at the Worcester $\mathrm{CHC}$, which is situated in the Boland-Overberg region of the Western Cape and serves the Breede Valley District, which has an estimated population of 160000 and one of the worst levels of poverty in the Western Cape. The commonest causes of adult mortality in this population are TB, cardiovascular disease and HIV/AIDS, and amongst children the causes are low birth weight, diarrhoea and respiratory infections. The $\mathrm{CHC}$ is responsible for the delivery of free comprehensive primary care services and sees up to 400 clients per day, which includes referrals from satellite clinics, this explains why doctors are present in the $\mathrm{CHC}$. Other services for TB, antenatal care, chronic diseases, family planning, child health and psychiatry were run as separate vertical sections in the $\mathrm{CHC}$.

Prior to this study, the four doctors and four CNPs worked separately, although the CNPs were located in close proximity to each other and saw patients presenting with acute illnesses. Other services, such as TB management, antenatal care, chronic disease clinic, family planning, child welfare and psychiatry were run as separate vertical sections in the $\mathrm{CHC}$. The CNPs rotated between these services on a threemonthly basis.

This study was inspired by the management of the $\mathrm{CHC}$, who had implemented a different model of care based on the creation of three practice teams in which doctors and CNPs worked together. In this model, patients who were previously seen separately by the CNPs, the doctors or the chronic disease clinic were integrated into three practice teams. This model lasted only a few months and the 'experiment' had left the staff with feelings of frustration and disappointment, although senior staff remained committed to the concept. As this $\mathrm{CHC}$ was unique in both its experience of attempting practice teams and in its willingness to continue experimenting with the concept, the initiating researchers suggested the formation of a co-operative inquiry group to explore how more effective clinical care teams of doctors and CNPs could be created.

\section{Method}

At an introductory meeting, the staff members were invited to participate in the co-operative inquiry group $(\mathrm{ClG}){ }^{13,14}$ The eight members of staff who committed themselves to the inquiry included the two facility managers (one a nurse), a consultant family physician, one of the medical officers, a chief professional nurse and the chief administrator. The $\mathrm{CIG}$ is a cyclical process of action, observation, reflection and planning, and this paper represents the findings of the first three cycles held over a period of nine months.

\section{Action}

The members of the $\mathrm{CIG}$ engaged in in-depth interviews with each other, one focus group discussion with the doctors and another with the nurses, a survey of patient opinions and medical records on continuity of care, and interaction with the staff at the routine staff, business and section meetings. As the members of the CIG were all active members of the $\mathrm{CHC}$, they also acted as participant observers and conducted numerous informal interviews. Attempts were made to integrate the preparation of acute and chronic patients in the $\mathrm{CHC}$ and to introduce better information on the availability and identity of the staff.

\section{Observation and documentation}

All interviews were audio-taped and members of the $\mathrm{CIG}$ wrote individual accounts of their actions. The individual narratives of action taken were also audio-taped at each CIG meeting. Qualitative and quantitative data collected by visiting medical students as part of the patient and medical record survey was summarised in a PowerPoint presentation. Key discussions in the 
CIG meetings were audio-taped and the facilitators also kept notes in newsprint and personal journals.

\section{Reflection}

The CIG reflected on the actions taken through the use of group discussion that emphasised reflective listening and clarification. All group discussions were audio-taped and a reflective summary was created and circulated at the end of each cycle. This documented the actions taken by each group member, the reflections of the group and the actions planned for the next cycle. Other techniques that were used to aid reflection were reflective writing, 'blind' writing, free attitude interviews and drawing.

\section{Planning}

Each individual had to commit himself or herself to specific actions during the next cycle. These plans were recorded in the reflective summary.

The CIG was facilitated by the two initiating researchers, who had prior experience in action research and facilitating small groups. They ensured that the CIG remained aligned with its purpose in terms of the actions and reflections and trained the group in the research methodology. These facilitators remained conscious of the need to build ownership of the inquiry and commitment to the group amongst all the members, and took responsibility for creating capacity in the group for personal reflexivity and reflection. The facilitators enabled a democratic and collaborative group dynamic that evoked a spirit of acceptance, reflective listening, equity and valuing each others' contributions.

The facilitation of the CIG raised a number of issues. One of the facilitators was not fluent in Afrikaans and therefore the CIG agreed to conduct itself in English, although members were free to speak Afrikaans. The members of the CIG all had established working relationships with each other that involved professional, organisational and personal dynamics. The facilitators attempted to create a space within the CIG where people related on a first name basis and were equally valued for their contribution to the dialogue. The members of the CIG were not familiar with the research methodology and initially expressed some reservation about the focus on personal reflexivity and reflection. One member of the group dropped out after the first cycle and subsequently moved to another hospital and was replaced. The second CIG cycle took much longer than expected due to the holiday season and, in general, the group had difficulty in establishing dates when all members were available during working hours. Nevertheless, the group remained aligned with its purpose and generated shared ownership of the inquiry, which culminated in a two-day meeting at the end of the third cycle. Not all the planned actions were implemented, but there was sufficient engagement in action to generate enough experience to serve as a basis for reflection and learning.

\section{Findings}

These first three cycles explored the successes and failures of the previous attempt at creating practice teams, the readiness of the staff to make further changes and ways in which these changes could be initiated. The group found that, in order for practice teams to work, the following are needed:

- A clear and shared vision and mission amongst the staff of the $\mathrm{CHC}$

- Changes in the behaviour and roles of staff in the $\mathrm{CHC}$

- Effective management of the change process

The key results are summarised in Table I.

A clear and shared vision and mission amongst the staff of the $\mathrm{CHC}$

The initial attempt to introduce practice teams was championed by the family physician, whose vision for the $\mathrm{CHC}$ was based on the principles of family medicine that included a commitment to continuity of care, family-oriented care, integration of vertical services within the practice team, enhanced practitionerpatient relationships and better collaboration between nurses and doctors. The principles had been presented to the $\mathrm{CHC}$ staff, but he had considered only the practice teams model as a means of implementation. This approach had not allowed for sufficient dialogue to create a genuinely shared vision among the staff and it was unclear whether these underlying principles were generally accepted.

The experience of the practice teams, in relation to each of the original underlying principles, will now be discussed.

\section{- Continuity of care}

A survey of 102 medical records found that approximately one-third of the patients saw the same practitioner at each visit, one-third saw the same practitioner in $50 \%$ of visits and one-third hardly ever saw the same practitioner. A patient sur- vey demonstrated support for the practice team concept in $67 \%$ of 72 patients. The practice team model was not supported by $14 \%$ of the respondents, as they were concerned about the different waiting times for the various practitioners and whether a second opinion would be an option if requested. A further $19 \%$ thought that the continuity of information in the medical record should be sufficient.

The doctors supported the principle of continuity of care, while reserving the need for second opinions and cross-referral. In reality, the three practice teams differed in the consistent availability of the same doctor, which undermined continuity. Only two of the teams had a dedicated doctor and the other relied on several doctors giving their time piecemeal and often only after completing their hospital duties. Continuity with the CNP was also undermined when patients were referred by a doctor from outside the $\mathrm{CHC}$ and bypassed the CNP. The CNPs were more ambivalent about the principle and some expressed concern that there would be less variety of experience and/or loss of clinical skills as a result of seeing the same group of patients. Each team attempted to introduce a booking system, and this was seen as being supportive of continuity. Overall, the $\mathrm{ClG}$ felt that the $\mathrm{CHC}$ practitioners had understood and accepted continuity of care as a key principle, although it had not yet been adequately implemented.

\section{- Family-orientated care}

The vision of practice teams anticipated more holistic family-orientated care, in which members of the same family would be seen in the same practice. This ideal was questioned, as many patients came from complex extended family households and did not represent traditional family structures. Examples were given of children in the same household who had different parents, parents who often were unmarried and had different surnames, children who often were accompanied by neighbours and/or given different names, and the composition of households constantly changing due to the seasonal nature of work opportunities in the area. Furthermore, some families with internal conflicts might resist being in the same practice teams. Overall, the $\mathrm{CIG}$ felt that this principle had met with only limited success.

\section{- Integration of care}

Attempts were made to integrate the care of patients with acute and chron- 
ic illnesses equally among the practice teams. The CIG found that the concept of "chronic patients" was deeply embedded in the mindset of the staff and appeared to include certain assumptions, such as that these were stable patients who were not expected to experience new or acute problems and who only required monitoring or repeat prescriptions. The temptation therefore was to ignore or postpone dealing with any new problems. It was postulated that integration into practice teams would allow a more responsive and holistic approach, although the practitioners who had previously dealt with the "chronics" continued to see a disproportionately high number in their new practice team. This appeared to be due to the inability to integrate the preparation of all patients in one observation room and the tradition of sending chronic patients to a specific doctor. There was discussion about integrating other services, such as antenatal care, but the staff felt that this was unrealistic and they were not ready to embrace the idea.

\section{- Enhanced practitioner-patient rela- tionships}

The benefits of having a committed and trusting relationship with the same practitioner were eroded by the unanticipated negative effects of the introduction of practice teams on patient waiting times. When the doctor was not available due to other duties in the local hospital, the patients attending that practice experienced longer waiting times. The long waiting time and inequality between teams led to frustration and even anger among the patients. This frustration was taken out on the CNPs and other nursing staff, despite their not being responsible for the absence of the doctors. The CNPs' frustration culminated in a crisis meeting, at which point they withdrew from the integrated practices and formed their own nurse-based practice team.

The teams that had a doctor available consistently reported that they believed they were providing a higher quality of care, with more time for the patients and better practitioner-patient relationships. From this experience it was realised that more accessible and detailed information was required as to when specific practitioners were going to be available and that the development of the practice teams required prioritisation of the doctor's time at the $\mathrm{CHC}$, as well as the employment of more full-time doctors. Although there was no fundamental disagreement with the above principles, all the staff expressed concern that the practice teams had not fulfilled their potential, and most were willing to consider further attempts to realise these principles if the pitfalls described above could be avoided in the future.

\section{Changes in the behaviour and roles of staff}

- Respect for different roles

The CIG found that some doctors still perceived a nurse as an "assistant" who could be called on to run errands or perform tasks and that this role was resented by the CNPs. Doctors considered themselves to be practitioners whose role it was to consult patients, while the CNPs regarded themselves primarily as specialist nurses who should rotate to other duties and perform a variety of tasks. The CNPs therefore did not want to remain as permanent members of the practice teams, while the doctors had no problem with this. The CNPs role oscillated between that of a practitioner who consulted patients and that of a nurse who performed basic observations and side-room tests. The doctors felt responsible for seeing a certain number of patients in the time they were available, while the CNPs felt responsible for getting all the patients through the $\mathrm{CHC}$.

\section{- Interaction between doctors and CNPS} The doctors were orientated towards patient care and did not create space for mentoring the CNPs, who were often seen as an intrusion and a threat to patient privacy and confidentiality when requesting a consultation. This was exacerbated when the doctors experienced a sense of overwhelming pressure from the patient load and entered a kind of "survival mentality" that only focused on "getting through the queue". For the CNPs, however, the advantage of practice teams was considered to be the greater accessibility to the doctor for joint consultation. Such accessibility would be convenient for the patient and be supportive of the CNP as a result of such constructive feedback, which would in turn facilitate her own clinical capacity and learning. The CNPs varied in their need to consult, with some being willing to report their own radiographs and others seeking help for basic decisions. CNPs also complained that their patient management was often unnecessarily delayed by waiting for a consultation with the doctor and that they were sometimes criticised or belittled in front of their patients. The identifica- tion of doctors and CNPs with each other as part of a functioning team did not materialise.

One solution suggested by the $\mathrm{CIG}$ was to create practice teams with clear role differentiation between nurse practitioners who consult and other professional nurses and nursing auxiliaries who support all the practitioners equally. The CIG also postulated that more open dialogue regarding roles, as well as more explicitly negotiated referral processes, might help in the future.

\section{Effective management of the change process}

The CIG reflected on the following factors that were important in managing the change process:

\section{- Sufficient staff}

Practice teams require enough practitioners who are committed over time, present throughout the day and who can maintain services during periods of leave. The failure of the $\mathrm{CHC}$ to provide sufficient doctors led to the critical breakdown of the practice teams.

\section{- Coherent infrastructure}

Practice teams require an infrastructure that is supportive of comprehensive and continuous care. The current design of the $\mathrm{CHC}$ is not coherent with a practice team model and, while there was sufficient space to create three separate teams, it was not possible to integrate the preparation of acute and chronic patients or for each team to have its own reception and observation areas. When all the members of the team were present, sufficient consulting space was a problem. In addition, there was a lack of basic infrastructure, such as telephones, in the consulting rooms. A restructuring of the $\mathrm{CHC}$ budget was also required to be coherent with the development of semiautonomous teams that might have different needs and priorities.

- Communication and decision making Insufficient time was spent negotiating with, listening to and informing the staff and patients about the planned changes and the rationale for them. There had been no patient consultation and no community committee existed in the $\mathrm{CHC}$. The implications of the change for the entire staff, and not just for the nurses and doctors, were not anticipated, particularly in relation to the administrative and reception staff. A preliminary consultation and discussion period might have anticipated some of the problems that subsequently occurred, 
Table 1: A summary of the key themes

\begin{abstract}
A clear and shared vision and mission amongst the staff of the $\mathrm{CHC}$
Staff largely accepted the principles of continuity of care, family-orientated care, integration of care and enhanced practitioner-patient relationships that were embedded in the practice team concept. This vision, however, was not jointly formulated and the realisation of these principles was limited by unanticipated consequences, such as unequal waiting times for the different practice teams.

\section{Changes in the behaviour and roles of staff in $\mathrm{CHC}$}

Doctors and nurses had different identities as practitioners, different assumptions about each other's roles and different expectations of the personal benefits of practice teams, which made it difficult for them to understand each other and work together.

\section{Effective management of the change process}

The inability to provide one consistently available doctor for each of the practice teams was instrumental in the breakdown of the teams. The physical infrastructure of the health centre constrained the development of ideal practice teams. The planning process did not engage all the health centre staff, even though the changes had an impact on all of them.
\end{abstract}

facilitating the development of a shared vision and providing alternative strategies to achieve the vision. Motivation and leadership from management to implement change are necessary, but should be preceded by sufficient space for dialogue so that the staff can express their concerns and opinions.

\section{Discussion}

This inquiry clearly demonstrates the difficulties of changing complex systems such as health care. Important findings included the need for different leadership styles, anticipating the unexpected consequences of change, better clarification of and respect for complementary roles, improved dialogue and communication, sufficient staffing levels, appropriate infrastructure and collaborative planning. Many of these barriers to change echo the findings of Hagebak, who also studied the South African context. ${ }^{15}$ The following discussion considers what lessons can be learnt from these results.

The initial attempt at creating practice teams followed a transactional leadership style, ${ }^{16}$ with one person with a strong sense of direction attempting to obtain agreement from the nursing and medical staff on what they could do to make his vision a reality. At the end of the three cycles, the CIG adopted a transformational leadership style, which places the leader at the centre of a network of relationships from which a vision can emerge through dialogue. ${ }^{16}$ The challenge to the CIG will be to transfer this approach into the leadership of the $\mathrm{CHC}$ as they reconsider what their shared vision and mission should be. In future, the patients should be included at all levels of this dialogue.

Consideration of the effects of change on the whole system would have been more likely in a dialogical planning process. Dialogue implies more than just talking to each other or attending a meeting, but an openness to acknowledge different and even contradictory viewpoints. ${ }^{17}$ The spirit of dialogue therefore affirms the equal validity of each participant's knowledge and expertise and welcomes questions or challenges as an essential part of collaboration. For collaboration and partnerships to develop, the potential partners need to believe in the "creative potential of joint working toward purposive change". ${ }^{15}$

This study suggests that both doctors and CNPs may need to evolve different understandings of their roles to meet the demands of primary care in a complex, resource-constrained setting in a developing country. CNPs may need to develop a stronger identity as practitioners and clinical colleagues who share a set of competencies that overlap more with those of the doctor than with other categories of nurses. Likewise, the doctor may need to develop an acceptance of his or her role as a mentor and as providing referral support to the CNP. This role may require a commitment to being available for consultation, as well as to developing interpersonal and communication skills that facilitate the provision of feedback in a supportive manner. Joint continuing professional development is an option that needs to be considered. Dialogue in order to develop a shared understanding of their roles, responsibilities and working relationships within a busy primary care setting is crucial to the offering of the best available care and treatment for the patient. Issues such as the clarification of assistance (e.g. observations, side-room tests) for both groups of practitioners, expectations of the process of doctor-CNP referral and consultation would have promoted more effective relationships. In addition, it was not clear how the leadership of the individual practice teams had been conceived, which resulted in conflict and feelings of resentment and frustration.

The physical structure of the clinic should be planned better so that the practice team model can be implemented. Consulting rooms and waiting, preparation and treatment areas require careful architectural planning that takes into account how patients will be linked to specific practice teams.

All the personnel need to be consulted and informed as to how the practice teams function. Lines of communication, opportunities for ongoing dialogue and problem solving need to be included in the health centre's working schedule.

Finally, the future success of the practice teams will depend on the consistent availability of senior doctors in each team. In this setting, where the doctors had local hospital responsibilities, this issue created particular timetabling challenges.

The implementation of the vision of creating practice teams at the Worcester $\mathrm{CHC}$ has met with limited success so far. Nevertheless, the members of the CIG intend to learn from the findings of this inquiry and, on the basis of their outcome mapping plan, ${ }^{18}$ to introduce new changes in the near future. The findings of this inquiry may also be transferred to the many similar primary care settings in South Africa and assist with the planning of more effective practice teams.

The following recommendations can therefore be made:

- Adopt a transformational leadership style

- Engage in a dialogical planning pro- 
cess that values people's concerns and opinions

- Equip doctors with skills to mentor and support CNPs

- Support the development of a unique professional identity for CNPs

- Facilitate open dialogue on the roles and responsibilities of doctors and CNPs

- Review how the physical infrastructure can be modified to better support semi-autonomous teams

- Involve all categories of staff in the planning and ensure ongoing dialogue with regard to the changes

- Ensure that doctors are available throughout the day in all the practice teams

- Consult with and prepare the patients for changes that are planned in the community health centre

\section{References}

1. May J. Poverty and inequality in South Africa: meeting the challenge. Cape Town: David Philip Publishers; 2000

2. Lehmann $U$, Blom W, Dlanjwa $M$, et al. Capacity development through reflective practice and collaborative research among clinic supervisors in rural South Africa: a case study. Education for Health 2004;17(1):53-61.

3. Boelen C, Haq C, Hunt V, Rivo M, Shahady E. Improving health systems: the contribution of family medicine. A guidebook. Singapore: WONCA (World Academy of Family Doctors), Bestprint Publications; 2002

4. Salvage J, Smith R. Doctors and nurses: doing it differently. BMJ 2000;320:101920.

5. Schlemmer A. Exploring the effects of a language barrier between the patients and staff at Hottentots Holland Hospital. [M Fam Med thesis]. Stellenbosch: Stellenbosch University; 2005.

6. Closs SJ. Interdisciplinary research and the doctor-nurse game. Clinical Effectiveness in Nursing 2001;5:101-3.

7. Larson $\mathrm{E}$. The impact of physician-nurse interaction on patient care. Holistic Nursing Practice 1999;13(2):38-46.

8. Temkin-Greener $\mathrm{H}$.. Interprofessional perspectives on teamwork in health care: A case study. Health and Society 1983;61(4):641-58.

9. Long A, McCann S, McKnight A, Bradley $T$. Has the introduction of nurse practitioners changed the working patterns of primary care teams?: A qualitative study. Primary Health Care Research and Development 2004;5:28-39.

10. Iliffe $S$. Nursing and the future of primary care. BMJ 2000;320:1020-1.

11. Kapp R, Mash B. Perceptions of the role of the clinical nurse practitioner in the Cape Metropolitan doctor-driven community health centres. SA Fam Prac J 2004;46(10):21-5

12. Van der Walt HM, Swartz L. Task orien- tated nursing in a tuberculosis control programme in South Africa: where does it come from and what keeps it going? Social Science \& Medicine 2002;54(7): 1001-9.

13. Mash B, Meulenberg-Buskens I. 'Holding it lightly': the co-operative inquiry group: a method for developing educational materials. Medical Education 2001;35:1108-14

14. Reason P. The co-operative inquiry group. In: Reason P, editor. Human inquiry in action. London: SAGE Publications; 1988. p. 18-39.

15. El Ansari W, Phillips C, Zwi AB. Public health nurses' perspectives on collaborative partnerships in South Africa. Public Health Nursing 2004;21(3):277-86.

16. Davies C. Getting health professionals to work together: There's more to collaboration than simply working side by side. BMJ 2000;320:1021-2.

17. Earl S, Carden F, Smutylo T. Outcome mapping. Building learning and reflection into development programs. Ottawa: International Development Research Centre; 2001.

18. Davies C. Getting health professionals to work together. BMJ 2000;320:1021-2. 